\title{
Public participation: methods matter; a response to Boaz et al.
}

\author{
Paul Burton ${ }^{1}$, Jennifer A Whitty ${ }^{2,}$, Elizabeth Kendall ${ }^{3}$, Julie Ratcliffe ${ }^{4}$, Andrew Wilson ${ }^{5}$, Peter Littlejohns ${ }^{6}$, \\ Paul A Scuffham ${ }^{3}$
}

*Correspondence to: Jennifer A Whitty, Email: j.whitty@uq.edu.au Copyright: ๑ 2014 by Kerman University of Medical Sciences

Citation: Burton P, Whitty JA, Kendall E, Ratcliffe J, Wilson A, Littlejohns P, et al. Public participation: methods matter; a response to Boaz et al. Int J Health Policy Manag 2014; 3: 355. doi: 10.15171/ijhpm.2014.108

Received: 15 October 2014, Accepted: 24 October 2014, ePublished: 26 October 2014

$\mathrm{T}$ The commentary on our paper from Boaz et al. is both welcome and pertinent, especially in its call for greater critical attention to be paid to some of the underlying principles of participation as well as to techniques and methods $(1,2)$. In some respects our paper and subsequent research was designed to allow us to measure and better understand the impact of participating in a citizen's jury on the jurors' views and expressed preferences $(1,3)$. This allowed us to develop a more rounded appreciation of the costs and benefits of practical forms of deliberative democracy. These practical investigations are, we believe, important when debating the principles of participation and in particular the concern raised by Boaz et al. about the achievement of 'genuine' participation (2). Ever since Arnstein proposed the concept of a ladder of participation in 1969 (4), there has been a tendency to impose a normative dimension onto what was essentially an analytical construct, such that moving up her ladder leads us towards more 'genuine' forms of participation and may even be seen as a stairway to participatory heaven (5). Our research offers further evidence of the potential for deliberative events, such as citizen's juries, to provide excellent opportunities for 'ordinary citizens' to engage in complex health policy debates and to make sophisticated contributions to them. But it also shows that this is an expensive process and it is difficult to imagine it being applied on a very wide scale to the full panoply of contemporary health policy concerns. One way forward is to move away from the notion that the active involvement of all citizens in all decisions that might affect them is the zenith of participation in practice and to ask ourselves a more modest set of questions every time we plan a participatory event (or are invited to join one). These include: who is being invited to join this event and what is the basis of the invitation (expertise, enthusiasm, demographic characteristic or randomness); what are the terms of engagement (informing, framing, debating, deciding) and what is the scale of engagement (strategic, programmatic or personal)? While there is no right answer to any of these questions, having an answer is especially important for we know that uncertainty and ambiguity on these dimensions underpins much of the dissatisfaction in practice with many participatory exercises and leads to serious concerns about how 'genuine' they are. The achievement of rights-based approaches to health in practice requires this kind of attention to detail both in theory and in practice.

\section{Ethical issues \\ Not applicable.}

Competing interests

Authors declare that they have no competing interests.

Authors' contributions

PB drafted the response, all authors reviewed the response for academic content and approved the final version.

\section{References}

1. Whitty JA, Burton P, Kendall E, Ratcliffe J, Wilson A, Littlejohns $P$, et al. Harnessing the potential to quantify public preferences for healthcare priorities through citizens' juries. Int $J$ Health Policy Manag 2014; 3: 57-62. doi: 10.15171/ijhpm.2014.61

2. Boaz A, Chambers M, Stuttaford M. Public participation: more than a method? Comment on "Harnessing the potential to quantify public preferences for healthcare priorities through citizens' juries". Int J Health Policy Manag 2014; 3: 291-3. doi: 10.15171/ijhpm.2014.102

3. Scuffham PA, Ratcliffe J, Kendall E, Burton P, Wilson A, Chalkidou $\mathrm{K}$, et al. Engaging the public in healthcare decisionmaking: quantifying preferences for healthcare through citizens' juries. BMJ Open 2014; 4: e005437. doi: 10.1136/ bmjopen-2014-005437

4. Arnstein S. A ladder of citizen participation. Journal of the American Institute of Planners 1969; 35: 216-24.

5. Burton P. Conceptual, Theoretical and Practical Issues in Measuring the Benefits of Public Participation. Evaluation 2009; 15: $263-84$.

\footnotetext{
${ }^{1}$ Urban Research Program, Griffith School of Environment, Griffith University, Gold Coast Campus, Southport, Queensland, Australia. ${ }^{2}$ School of Pharmacy, Faculty of Health and Behavioural Sciences, The University of Queensland, Brisbane, Queensland, Australia. ${ }^{3}$ Griffith Health Institute, Griffith University, Logan Campus, University Drive, Meadowbrook, Queensland, Australia. ${ }^{4}$ Flinders Health Economics Group, School of Medicine, Flinders University, Adelaide, Australia. ${ }^{5}$ Menzies Centre for Health Policy, University of Sydney, New South Wales, Australia. ${ }^{6}$ Division of Health and Social Care Research, Faculty of Life Sciences and Medicine, London, UK.
} 